\title{
Descriptive Study of Hepatitis B, C and HIV Infections and Associated Factors among Adult Population in Kabul City, 2015
}

\author{
Khwaja Mir Islam Saeed (MD, MSc) ${ }^{1}$ \\ ${ }^{1}$ Head of Grant and Service Contract Management Unit (GCMU), Ministry of Public Health, Kabul- \\ Afghanistan, Tel: 0093700290955
}

\begin{abstract}
Background: Viral infections are global public health problem. Shortage of information about Hepatitis B Virus (HBV), Hepatitis C Virus (HCV) and HIV/AIDS prevalence in Afghanistan is very clear. This study aimed to describe the prevalence and risk factors associated with HBV, HCV and HIV infection among adult population of Kabul city.

Methods and Materials: A province based cross-sectional survey among adult population (25-70 years) of Kabul city was conducted in November, 2015 using a WHO STEP wise tool. A total of 1174 adult citizens in Kabul city were included in the study. Demographic, socioeconomic and lifestyle factors were collected by face to face questionnaire. Blood samples were collected and rapid tests were used to find the prevalence of $\mathrm{HBV}$, HCV, and HIV infections. Data management was done using Epi info v.7 and SPSS v.20.

Results: The overall prevalence of HBV using HBsAg and Anti-HCV rapid tests were $3 \%(35 / 1174)$ and $1.1 \%$ (13/1374) respectively. Only two individuals were positive for HIV infection out 100 samples under confirmatory test. Of total 1174 records females constituted almost half $599(51 \%)$ with overall mean age of $38.6 \pm 12.2$ years. Females were slightly more in all age groups. Approximately half of the respondents $(49.6 \%)$ were illiterates while the proportion of illiteracy was more in all age groups. Two third of the study subjects were married (77.5\%) and $60 \%$ of women were housewives. Risky behaviors such as tattooing, hospitalizations, history of jaundice, living with hepatitis patients and undergoing dental procedures were common among positive subjects.

Conclusion: A prevalence rate of 3\%, 1.1\% for HBsAg and anti-HCV and two cases of HIV infection apparently represents a trigger point for action in Kabul city. Public awareness and health education regarding risk factors for viral hepatitis and encouragement for vaccination is recommended. National program for blood borne viral diseases are an axis for focus of government and donors.
\end{abstract}

Keywords: $H B V, H C V$, HIV infection, Hepatitis, risk factors, Kabul, Afghanistan

\section{INTRODUCTION}

Hepatitis B and C viral infections are recognized as global health problems that are transmitted through contact with the blood or other body fluids. They attack the liver causing both acute and chronic disease. Viral hepatitis affects 400 million people globally and 6-10 million people are newly infected each year. Globally, about 1.4 million people die each year from hepatitis. An estimated 240 million people are chronically infected with hepatitis B while more than 650,000 people die annually due to its complications including cirrhosis and liver cancer. Besides Hepatitis B is an important occupational hazard for health workers. However, it can be prevented by currently available safe and effective vaccine [1]. The WHO strategy on viral hepatitis addresses the axes such as awareness-raising, partnerships and resource mobilization; evidence-based policy and data for action; prevention of transmission and screening, care and treatment [2].

The hepatitis $\mathrm{C}$ virus is a blood borne virus transmitted through unsafe injection practices, inadequate sterilization of medical equipment, and the transfusion of unscreened blood and blood products. Globally, around 150 million people have chronic hepatitis $\mathrm{C}$ infection and a significant number of those who are chronically infected will develop liver cirrhosis or liver cancer. Approximately 700000 people die each year from hepatitis C-related liver diseases. Antiviral medicines can cure approximately $90 \%$ of persons with hepatitis $\mathrm{C}$ infection, thereby reducing the risk of death from liver cancer and cirrhosis, but access to diagnosis and treatment is low [3]. Most of the patients with HCV are asymptomatic till the disease is at its terminal stage posing a great danger to spread this infection silently [4]. There is currently no vaccine available for HCV infection prevention due to the high degree of strain variation but the struggles are ongoing [5].

Human Immunodeficiency Virus (HIV) continues to be a major global public health issue. In 2015 around one million people died from HIV-related causes globally. There were approximately 36.7 million people living with HIV at the end of 2015 with 2.1 million people becoming newly infected globally. SubSaharan Africa is the most affected region, with 25.6 million people living with HIV in 2015. HIV infection is often diagnosedthrough rapid diagnostic tests (RDTs), which detect the presence or absence of HIV antibodies 
and provide same-day test results. There is no cure for HIV infection. However, effective antiretroviral (ARV) drugs can control the virus and help prevent transmission so that people with HIV, and those at substantial risk, can enjoy healthy, long and productive lives. Between 2000 and 2015, new HIV infections fell by 35\%, AIDSrelated deaths fell by $28 \%$ with some 8 million lives saved. This achievement was the result of great efforts by national HIV programs supported by civil society and a range of development partners. Expanding ART to all people living with HIV and expanding prevention choices can help avert 21 million AIDS-related deaths and 28 million new infections by 2030 [6].

There are variations in prevalence of $\mathrm{HBV}$ around the globe. In a study which was conducted in Iran the overall prevalence of $\mathrm{HBV}$ was $3 \%$ and its distribution varied in different provinces from $0.87 \%$ to $8.86 \%$ [7]. In Brazil the prevalence of $\mathrm{HBV}$ in elderly was $0.6 \%$ with positive $\mathrm{HBsAg}$ and $15.1 \%$ with anti-HBc reactive. Variables remained independently associated with HBV infection were male gender, marital status, $\leq 4$ years of schooling and acupuncture [8]. A cross sectional study in Nigeria among university students reported that the seroprevalence of $\mathrm{HBsAg}$ was $8.3 \%$ out of which $26.7 \%$ were positive for $\mathrm{HBeAg}, 53.3 \%$ had $\mathrm{HBeAb}$, $20 \%$ had neither HBeAg nor HBeAb, $100 \%$ had total HBcAb and $86.7 \%$ had HBV DNA in their serum [9]. A nationwide survey in Romania showed that the overall prevalence rate of HBV chronic infection was $4.4 \%$. The personal history of blood or blood product transfusion, surgical interventions, tattooing, and alcohol consumption greater than $60 \mathrm{~g} /$ day were risk factors associated with HBV[10].

Furthermore there are similar variations on facts and rates of Hepatitis $\mathrm{C}$ virus. For instance the highest chronic infection rate of Hepatitis C was reported in Egypt (22\%), Pakistan (4.8\%) and China (3.2\%) [1]. Risk factors for HCV is not properly known by community in Pakistan. For example in a study conducted in Pakistan majority of $\mathrm{HCV}$ positive respondents had misperceptions of water, food, heat, and mosquitoes as the major factors of HCV transmission. While history of therapeutic injections/year, surgery, shaving at barber's shop, sharing tooth brush, razor and maswak, was more in HCV positive respondents [11]. In a study in Morocco the $\mathrm{HCV}$ and $\mathrm{HBV}$-seropositivity was documented in $1.58 \%$ and $1.81 \%$ of participants respectively from the general population. Two patients were found to be co-infected. Gender was not associated with HCV but risk factors for acquiring HCV infection were identified; age, dental treatment, use of glass syringes and surgical history. In addition to these factors, gender and sexual risk behaviors were found to be associated with higher prevalence of hepatitis B [12].

Very few studies conducted on blood born viral diseases including HBV, HCV and HIV infection due to other competing priorities. A review study reported that the prevalence was $1.9 \%$ for $\mathrm{HBV}$ and $1.1 \%$ for $\mathrm{HCV}$ in all Afghanistan population. Most at risk population to hepatitis include injecting drug users and female sex workers, while truck drivers, prisoners and homosexual men needs attention. This review was based on analysis of the limited available data in Afghanistan [13]. According to a meta-analysis prevalence of HCV in Afghanistan estimated at $0.7 \%$ among the general population and $31.8 \%$ among people who inject drugs (PWID) and $2.5 \%$ among populations at intermediate risk. The prevalence of HCV among PWID appeared to decline over few years from $36.0 \%$ to $27.6 \%$ in Kabul, from $12.5 \%$ to $9.5 \%$ in Jalalabad, and from $24.1 \%$ to $18.8 \%$ in Mazar-e-Sharif, it increased from $49.1 \%$ to $70 \%$ in Herat. Among prisoners, HCV prevalence appeared to increase from $1.7 \%$ to $4.6 \%$ in Kabul and declined from $4.1 \%$ to $1.4 \%$ in Herat. Risk factors among PWID included a range of injecting behaviors and socio-demographic characteristics. It means that HCV prevalence among the general population in Afghanistan is comparable to developing and developed countries globally [14]. Higher prevalence of hepatitis viruses has been reported among Afghan refugee populations outside of Afghanistan may raise the concern of elevated prevalence of hepatitis within the country [15]. In a study a total of 2166 Afghan national were included in the study who underwent surgery in a hospital in Peshawar Pakistan, 104 patients $(4.8 \%)$ were found to be positive for HBV. Re-use of unsterilized syringes and history of previous surgery were the most common risk [16]. In a real-time PCR assay with a set of primers and probe amplified core protein region of HBV genome the HBV DNA was detected in $79.7 \%$ of serum samples. The comparison of viral loads between the age groups and sex indicated no significant correlation, however, the serum HBV DNA level significantly decreased in the treated patient group [17]. In another study of female sex workers the prevalence of HIV was $0.19 \%$, HCV was $1.92 \%$, and HBV was 6.54 . HBV was associated age, ever using alcohol, anal sex and having children [18]. In a cross-sectional sample of adult injection drug users (IDUs) in Kabul, Afghanistan it was reported that the overall prevalence of HIV, HCV, and HBsAg were 3.0\%, 36.6\% and $6.5 \%$ respectively. Among male IDUs risky behavior, including sharing syringes, paying women for sex and having sex with men or boys were common [19]. Viral hepatitis has been a significant health risk for outsiders including US coalition, peacekeepers, and humanitarian workers deployed to Afghanistan. Viral hepatitis was a serious problem for Russian troops during the Soviet Union's incursion into Afghanistan in the 1980s [20]. A cross-sectional survey of hepatitis B surface antigen (HBsAg) was conducted during October 2003 reported that blood specimens of $8.3 \%$ were positive for HBsAg. Out of 301 children, 17 (5.6\%) were positive for HBsAg[12]. In a cross sectional study of adult participants undergoing treatment for tuberculosis $0.2 \%$ were HIV-infected [21]. A study on children in which a total of 330 children from outpatients clinics were included 
showed that the frequency of positive results for HBsAg, anti-HBs and anti-HCV in all age groups were 12 $(3.6 \%), 47(14.2 \%)$ and $2(0.6 \%)$, respectively. Anti-HIV was not detected in any of the children's serum [22]. A study in Jalalabad city among adult citizens reported that only 45 participants out of $1200(3.8 \%)$ were seropositive for HBsAg on rapid test and 41 (3.4\%) were confirmed positive after ELIZA test. Totally 11 subjects $(0.9 \%)$ were seropositive for anti-HCV on rapid tests. Both infections coexisted in none of participants and no one was positive for HIV infection. By multivariate logistic regression analysis, independent predictors for HBsAg infection were being male, traditional practice of tattooing and history of jaundice [23]. Another study in Mazar-e-Sharif reported that the prevalence of HBV was 5.6\% (69 out of 1231) for HBsAg on rapid test and $67(5.4 \%)$ were confirmed positive after ELIZA test. Totally 3 subject $(0.2 \%)$ were seropositive for anti-HCV on rapid tests. By multivariate logistic regression analysis, independent predictors for $\mathrm{HBsAg}$ infection were sex, history of jaundice, blood transfusion and living with hepatitis patients [24].Due to years of war and conflict in Afghanistan few studies conducted on infectious as well as noncommunicable diseases. The main objective of this article is to describe the prevalence of HBV, HCV and HIV infections and risky behaviors among adult citizens in Kabul city.

\section{METHODS AND MATERIALS}

Using WHO STEP wise tool a cross-sectional study was conducted in November to identify the main risk factors for noncommunicable disease among Kabul citizens. The tool is consists of three steps such as measuring socioeconomic and behavioral risk factors, physical measurements, and measuring biological risk factors [25]. Taking this opportunity the questionnaire were revised the variables commonly associated with blood borne diseases such as HBV, HCV and HIV infection were included in the questionnaire and blood samples collected and tested both for biochemical factors and mentioned viral infections by using rapid tests. For this study a general approval was given by the institutional review board (IRB) of the Ministry of Public Health and informed consent was taken from each individual before the interview. The results of physical and biochemical measurements communicated to required participants and the confidentiality of the information gathered was maintained.

Adult individuals of 25-70 years were included in the study. Assuming the highest prevalence (50\%), $95 \%$ confidence interval (CI) and margin of error of 5\%, a sample size of 385 subjects was calculated to include in the study. However, considering the proportion of other risk factors and design effect of 2 the final sample size was 1200. The 2015 Expanded Programme for Immunization (EPI) list of clusters was used as the sampling technique. We used multistage cluster sampling; in the first stage, from the list we conventionally selected five districts using random number in excel sheet. In the second stage from each selected district we randomly selected the 2 cluster; later the overall sample of 1200 household distributed among these selected area according to the proportion to the size of household number in each districts/ areas. Finally, the number of households in each area divided by the sample size assigned for each areas, it was enable us to select household systematically. The adapted questionnaire used by interviewers which covered information on demographic, behavioral and physical measurements. A household was defined as a group of people who share the same food pot (not the same roof). Blood samples were collected after filling the questionnaire by another experienced health worker the next morning and were transported in cold boxes $\left(2-8^{\circ} \mathrm{C}\right)$ from field to Central Public Health Laboratory (CPHL) in Kabul. On arrival in CPHL all serum samples were stored at $-80^{\circ} \mathrm{C}$ and later on were tested biochemical markers and tested for HBV, HCV, HIV infection using rapid tests. Data management and analysis was done using Epi-info, version 7 and SPSS, version 20.

\section{RESULTS}

This study describes the prevalence of blood borne infections such HBV, HCV and HIV infections in Kabul urban adults' population. It also describes and factors involved in transmission of such infections. Of total 1174 records females constituted almost half $599(51 \%)$ with overall mean age of $38.6 \pm 12.2$ years. Females were slightly more in all age groups. Three-fourth (75\%) of the study participants were aged less than 45 years. Approximately half of the respondents $(49.6 \%)$ were illiterates while the proportion of illiteracy was more in all age groups. Two third of the study subjects were married $(77.5 \%)$ and $60 \%$ of women were housewives (Table 1).

The prevalence of HBV was 3\% (35 out of 1174) for HBsAg on rapid test. Totally 13 subject (1.1\%) were seropositive for anti-HCV on rapid tests. All samples were tested for HIV infection using rapid tests and none were positive. Furthermore 100 serums including all HBV and HCV positives (rest of them negatives) were sent for further testing to Ankara, Turkey. As a result of serological testing for HIV Ag/Ab two individuals were positive for HIV infection. So we can claim that the prevalence of HIV infection is $2 \%(2 / 100)$ among adult population in Kabul city. In addition there was only one person with co-infection of HBV and HCV.

Use of tobacco was measured asking cigarette smoking and mouth snuff using. Eight percent of the study participants were current smokers and about half of them had smoking duration of 10 years. However smoking 
proportions differed from 5 to $9 \%$ among age groups highest in younger ones. Similarly, the general prevalence of snuff use was $(9.8 \%)$ predominantly among males while it was diluted due to low prevalence of snuff use in females $(2 \%)$. Sixty-six percent knew hepatitis. Table 2 reflects information on risk factors contributing in transmission of blood borne viral infections. In last six month ahead of field data collection $4.5 \%$ had blood transfusion; $2.3 \%$ had undergone surgery procedures and $18.1 \%$ undergone dental procedures. History of having jaundice was prevalent in $2.6 \%$ while one third $(34 \%)$ of them taken injection in last six months. Some behaviors such as piercing and traditional tattooing was reported in $31.7 \%$ mostly in females and $1.9 \%$ of study subjects respectively. Almost $2.4 \%$ went to hospitals in last six months and $10.7 \%$ had lived with a person who had hepatitis. Coverage of vaccination for hepatitis B was $6.2 \%$. Almost one third of participants (30.6\%) went to simple barber shops while the other two thirds were using modern barber shop or not using it being females. Proportion of blood transfusion ranged from 4\% to 7\% among age groups with highest among 45-55 years. Surgery procedures ranged from $1 \%$ to $6 \%$ among age groups with highest among older age groups. The rest of variables are explained with differentiation of age groups in frequency table.

Table 3 explains the prevalence of HBV and HCV by age categories among groups having various risky behaviors. Due to low number of positive cases it is difficult to identify statistical difference among groups. Prevalence of HBV was highest in young age groups (25-35) years while the prevalence of HCV was highest among highest age groups. However this difference was not statistically significant. Hepatitis B were more prevalent in males $23 / 35$ (66\%) as compare to females $12 / 35$ (34\%). Hepatitis C prevalence was high in females $9 / 13(69 \%)$ and low in females $4 / 13(31 \%)$. The prevalence of HBV was equaling in level of education while HCV was more prevalent in illiterates $8.13(62 \%)$. Almost two third of study subjects among positives and negatives in HBV and HCV had knowledge of viral hepatitis. Practice of blood transfusion was equal $5 \%$ and $6 \%$ among positive and negative cases of HBV while none of HCV positive cases had any practice of blood transfusion. Undergoing surgery procedures were similar in all groups but the practice of undergoing dental procedures were more in positive as compare to negative in both HBV (18\%vs 24\%) and HCV (18\%vs 23\%). The proportion of having history of jaundice was $18 \%$ in cases of HBV as compare to $2 \%$ in negative samples. HCV positives did not have any history of jaundice. Almost 33\% of HBV negatives practiced piercing and $10 \%$ of HBV positive practice piercing. The same finding is found for $\mathrm{HCV}$ as well. This is a controversial findings and require more in-depth and further studies. Practice of tattooing was not different in HBV positive or negatives but it was much different among HCV positive (8\%) and negatives (2\%). Hospitalization was more common among HBV positives (9\%) as compare to negatives (2\%) but no data was available for HCV. We did not have data on having lived under one roof with HCV patients but it was in double in HBV positives (21\%) as compare to negative cases of HBV (10\%). Just $6 \%$ of patients said they have been vaccinated against HBV while due to poor knowledge of $\mathrm{HCV}$ virus few subjects reported being vaccinated against $\mathrm{HCV}$ as well.

\section{DISCUSSION}

There is very few information available in Afghanistan on both communicable and noncommunicable diseases. The prevalence of and HBsAgseropositivityHBc antibody in the current study was 3\% and1.1\%, respectively. These values are similar to those reported in other provincial research papers reported from Jalalabad and Mazar-e-Sharif [13, 23-24]. The prevalence of the HCV antibody was high in men, older subjects, and illiterates. Furthermore two case of HIV infection tested positive in Ankara Turkey is main concern. The overall prevalence of HIV/AIDS infection in general population is reported to be $<0.5 \%$. Therefore, finding of this study although few cases could trigger the point that it is four-fold of general population and more focus should be given for further advanced studies in this regards. Such findings were zero in Jalalabad as well as Mazar studies apparently[23-24]. Probably that would be due to validity of rapid test which will require more confirmatory tests. Identification of such prevalence in adult population is first of its kind in this city but still due to lack of data from large parts of county efforts are required to strengthen national surveillance supported by lab components to assess the exact situation of viral hepatitis. The level of prevalence of all HBV, HCV and HIV infection seems low but having more proportion of high risk groups it could be projected to increase due to poor health education, low literacy level and weak health system. There is just national control program of tuberculosis, HIV/AIDS and malaria. There is a need to have a national control program for all kinds of hepatitis supported by government and donors. Findings reflected young generation were more positive for HBV and that could be due to involvement of this group in using of injections drugs which is a key driver of blood born viral transmission and probably owing to sharing the needles [26]. Undergoing dental procedures, tattooing and hospitalization were more common among HBV positives. These are known risk factors for such blood borne viral diseases and have been reported elsewhere as well [27]. Past history of jaundice was also prevalent in positive cases versus negative cases. Probably it could be a reason for their early exposure for virus which is not diagnosed timely. These findings are reported in literature by other studies as well [28].Despite of having shown the first time prevalence of blood born infection including HBV, HCV and HIV infection among general adult population in Kabul city, there were some limitations as well. The study was not designed initially for purpose 
of this study and confirmatory tests were not available in the country to approve the rapid tests. Although the burden seems low but due to low public awareness, risky behaviors, weak health system with tens other priorities more attention is needed to be given to this problem. A combine national program for prevention and control of viral blood born infections are recommended and widespread and national vaccination against HBV is encouraged particularly health workers should be prioritized. The national policy for health [29] and national health strategy [30] are developed recently in Ministry of Public Health in which attention is given to communicable disease including HBV, HCV and HIV/AIDS infection, however, the departments, programs, planners and donors should design some informed and practical strategies regarding these critical viral diseases to be tailored with local problems.

\section{ACKNOWLEDGEMENTS}

The author express gratitude to Surveillance Department at the Ministry of Public Health and the WHO Kabul office for supporting the main study. The CPHL is acknowledged for their processing and testing of HBV, HCV and HIV infections.

\section{REFERENCES}

[1] WHO. Media Centre Hepatitis B fact sheet. Update July 2016. Available from: http://www.who.int/mediacentre/factsheets/fs204/en/

[2] Prevention and control of viral hepatitis infection: framework for global action. Geneva, WHO, 2012.

[3] WHO. Hepatitis C fact sheet. Updated July 2016. Available from: http://www.who.int/mediacentre/factsheets/fs164/en/

[4] WHO. HIV/AIDS fact sheet. Updated July 2016. Available from: http://www.who.int/mediacentre/factsheets/fs164/en/

[5] Ashfaq UA, Javed T, Rehman S, Nawaz Z, Riazuddin S. An overview of HCV molecular biology, replication and immune responses. Virology journal. 2011; 8:161.

[6] Hayashi J, Kishihara Y, Yamaji K, Yoshimura E, Kawakami Y, Akazawa K, et al. Transmission of hepatitis $\mathrm{C}$ virus by health care workers in a rural area of Japan. The American journal of gastroenterology. 1995;90(5):794.

[7] Mohammadi Z, et al. Epidemiological Profile of Hepatitis B Virus Infection in Iran in the Past 25 years; A Systematic Review and Meta-analysis of General Population Studies.2016. Middle East J Dig Dis.Jan; 8(1): 5-18. doi: 10.15171/mejdd.2016.01

[8] Machado DFGP, et al. Prevalence and Factors Associated with Hepatitis B Virus Infection Among Senior Citizens in a Southern Brazilian City. Hepat Mon. 2013 May; 13(5): e7874. doi: 10.5812/hepatmon.7874

[9] Anaedobe CG, Fowotade A, EweanC, Omoruyi, Bakare RA. Prevalence, socio-demographic features and risk factors of Hepatitis B virus infection among pregnant women in Southwestern Nigeria. Pan Afr Med J. 2015; 20: 406. doi: 10.11604/pamj.2015.20.406.6206

[10] Gheorghe L, Csiki IE, Iacob S, Gheorghe C. The prevalence and risk factors of hepatitis B virus infection in an adult population in Romania: a nationwide survey. Eur J GastroenterolHepatol. 2013 Jan;25(1):5664. doi: 10.1097/MEG.0b013e328358b0bb

[11] Ali A, Khalid SN, Qureshi H. Assessment of Knowledge Regarding Risk Factors of Hepatitis C Virus Transmission and Options to avoid them. International Journal of Collaborative Research on Internal Medicine \& Public Health. 2015;7(9):190-203

[12] BahaW, et al. Prevalence and risk factors of hepatitis B and C virus infections among the general population and blood donors in Morocco. BMC Public Health2013; ( 13)50. DOI: 10.1186/1471-2458$13-50$

[13] Khan and Attaullah: Share of Afghanistan populace in hepatitis B and hepatitis C infection's pool: is it worthwhile? Virology Journal 2011 8:216.

[14] Chemaitelly H, Mahmud S, Abu-raddad LJA. The epidemiology of hepatitis c virus in Afghanistan: a systematic review and meta-analysis. Abstract (P10 15) Sex Transm Infect 2015;91(Suppl 2):A1-A258

[15] Quddus A, Luby SP, Jamal Z, Jafard T: Prevalence of hepatitis B among Afghan refugees living in Balochistan, Pakistan. International Journal of Infectious Diseases 2006, 10(3):242-247.

[16] Ahmad Khan Z, Shafiq M, Shahab F. Frequency and risk factors of hepatitis b \& c in afghan patients Presenting to tertiary care hospital in Peshawar. Pak Armed Forces Med J 2015; 65(5): 686-89

[17] Behzadi MA, ZiyaeyanM, SadafAsaeiS.Hepatitis B virus DNA level Among the Seropositive Afghan Immigrants, Southern Iran. Jundishapur J Microbiol. 2014 May; 7(5): e10127. DOI: 10.5812/jjm.10127 
[18] Todd CS, eta al. HIV, hepatitis B, and hepatitis C prevalence and associated risk behaviors among female sex workers in three Afghan cities. AIDS. 2010 July ; 24(0 2): S69-S75. doi:10.1097/01.aids.0000386736.25296.8d

[19] Todd CS, et al. HIV, Hepatitis C, and Hepatitis B Infections and Associated Risk Behavior in Injection Drug Users, Kabul, Afghanistan. Emerging Infectious Diseases • www.cdc.gov/eid • Vol. 13, No. 9, September 2007

[20] Wallace MR, et al. Endemic Infectious Diseases of Afghanistan. Endemic Infectious Diseases of Afghanistan • CID 2002:34 (Suppl 5)

[21] Todd CS, et al. Prevalence of Human Immunodeficiency Virus Infection, Risk Behavior, and HIV Knowledge among Tuberculosis Patients in Afghanistan. Sexually Transmitted Diseases, 2007; 34(11):878-882

[22] TanjuIA, Levent F, Sezer RG, Cekmez F. Hepatitis B, Hepatitis C and Human Immunodeficiency Virus Seropositivity among Children in Kabul, Afghanistan: A Cross-Sectional Study. Hepat Mon. 2014 March; 14(3): e16154. DOI: 10.5812/hepatmon.9036

[23] Saeed, KMI. Prevalence and Associated Factors of Hepatitis B, Hepatitis C and HIV Infection in Jalalabad City, Afghanistan. Ghazanfar Medical Journal. 2016;(01)6: 62-74

[24] Saeed, KMI. Prevalence and associated factors of Hepatitis B, Hepatitis C and HIV infections among adult citizens in Mazar-e-Sharif city, Afghanistan. IOSR Journal of Pharmacywww.iosrphr.org. (e)-ISSN: 2250-3013, (p)-ISSN: 2319-4219 Volume 6, Issue 11Version. 2 (Nov 2016), PP. 61-72

[25] Bonita R, deCourten M, Dwyer T, Jamrozik K, Winkelmann R. Surveillance of risk factors for noncommunicable diseases: the WHO STEP-wise approach. Geneva: World Health Organization; 2002 (WHO/NMH/CCS/01.2002).

[26] United Nations General Assembly Special Session on HIV/AIDS, Country Progress Report (Reporting Period January 2008 to December 2009). Islamic Republic of Afghanistan; 2010

[27] Ghadir, MR et al (2012). Distribution and Risk Factors of Hepatitis B Virus Infection in the General Population of Central Iran. Hepatitis Monthly, Vol. 12 Issue 2, p112

[28] Pasha O, Luby SP, Khan AJ, Shah SA, McCormick JB, Fisher-Hoch SP. Household members of hepatitis $\mathrm{C}$ virus-infected people in Hafizabad, Pakistan: infection by injections from health care providers. Epidemiol Infect 1999; 123:515-8.

[29] National Health policy 2015-2020. Ministry of Public Health, Islamic State of Afghanistan, Kabul 2015

[30] National Health Strategy 2016-2020: Sustaining Progress and Building for Tomorrow and Beyond. Ministry of Public Health, Islamic State of Afghanistan, Kabul 2015

Table 1: Demographic characteristics and behaviors of the study participants, Kabul city

\begin{tabular}{|c|c|c|c|c|c|c|c|c|c|}
\hline \multirow[b]{2}{*}{ Variables } & \multirow[b]{2}{*}{ Categories } & \multicolumn{2}{|c|}{ 25-34 years } & \multicolumn{2}{|c|}{ 35-44 years } & \multicolumn{2}{|c|}{ 45-54 years } & \multicolumn{2}{|c|}{$55+$ years } \\
\hline & & $\mathbf{N}$ & $\%$ & $\mathbf{N}$ & $\%$ & $\mathbf{N}$ & $\%$ & $\mathbf{N}$ & $\%$ \\
\hline \multicolumn{10}{|l|}{ Sex } \\
\hline & Female & 301 & $51 \%$ & 158 & $55 \%$ & 89 & $54 \%$ & 51 & $51 \%$ \\
\hline & Male & 291 & $49 \%$ & 131 & $45 \%$ & 76 & $46 \%$ & 75 & $49 \%$ \\
\hline & Total & 592 & $100 \%$ & 289 & $100 \%$ & 165 & $100 \%$ & 126 & $100 \%$ \\
\hline \multicolumn{10}{|c|}{ Level of Education } \\
\hline & Illiterate & 257 & $45 \%$ & 154 & $57 \%$ & 82 & $52 \%$ & 82 & $68 \%$ \\
\hline & Primary and unofficial & 96 & $17 \%$ & 55 & $20 \%$ & 34 & $22 \%$ & 17 & $14 \%$ \\
\hline & Secondary school & 139 & $24 \%$ & 43 & $16 \%$ & 31 & $20 \%$ & 13 & $11 \%$ \\
\hline & High school and over & 78 & $14 \%$ & 20 & $7 \%$ & 11 & $7 \%$ & 9 & $7 \%$ \\
\hline & Total & 570 & $100 \%$ & 272 & $100 \%$ & 158 & $100 \%$ & 121 & $100 \%$ \\
\hline \multicolumn{10}{|c|}{ Job Categories } \\
\hline & Official Employees & 98 & $17 \%$ & 43 & $15 \%$ & 22 & $13 \%$ & 173 & $8 \%$ \\
\hline & Students & 17 & $3 \%$ & 0 & $0 \%$ & 0 & $0 \%$ & 17 & $0 \%$ \\
\hline & Private Business & 25 & $4 \%$ & 12 & $4 \%$ & 10 & $6 \%$ & 55 & $6 \%$ \\
\hline & Worker/Farmer & 35 & $6 \%$ & 25 & $9 \%$ & 8 & $5 \%$ & 77 & $7 \%$ \\
\hline & Jobless & 28 & $5 \%$ & 17 & $6 \%$ & 7 & $4 \%$ & 61 & $7 \%$ \\
\hline & Housework & 187 & $32 \%$ & 108 & $38 \%$ & 51 & $31 \%$ & 368 & $18 \%$ \\
\hline & Unable to work/no response & 200 & $34 \%$ & 82 & $29 \%$ & 66 & $40 \%$ & 415 & $54 \%$ \\
\hline & Total & 590 & $100 \%$ & 287 & $100 \%$ & 164 & $100 \%$ & 1166 & $100 \%$ \\
\hline
\end{tabular}


Descriptive Study of Hepatitis B, C and HIV Infections and Associated Factors among Adult Population in

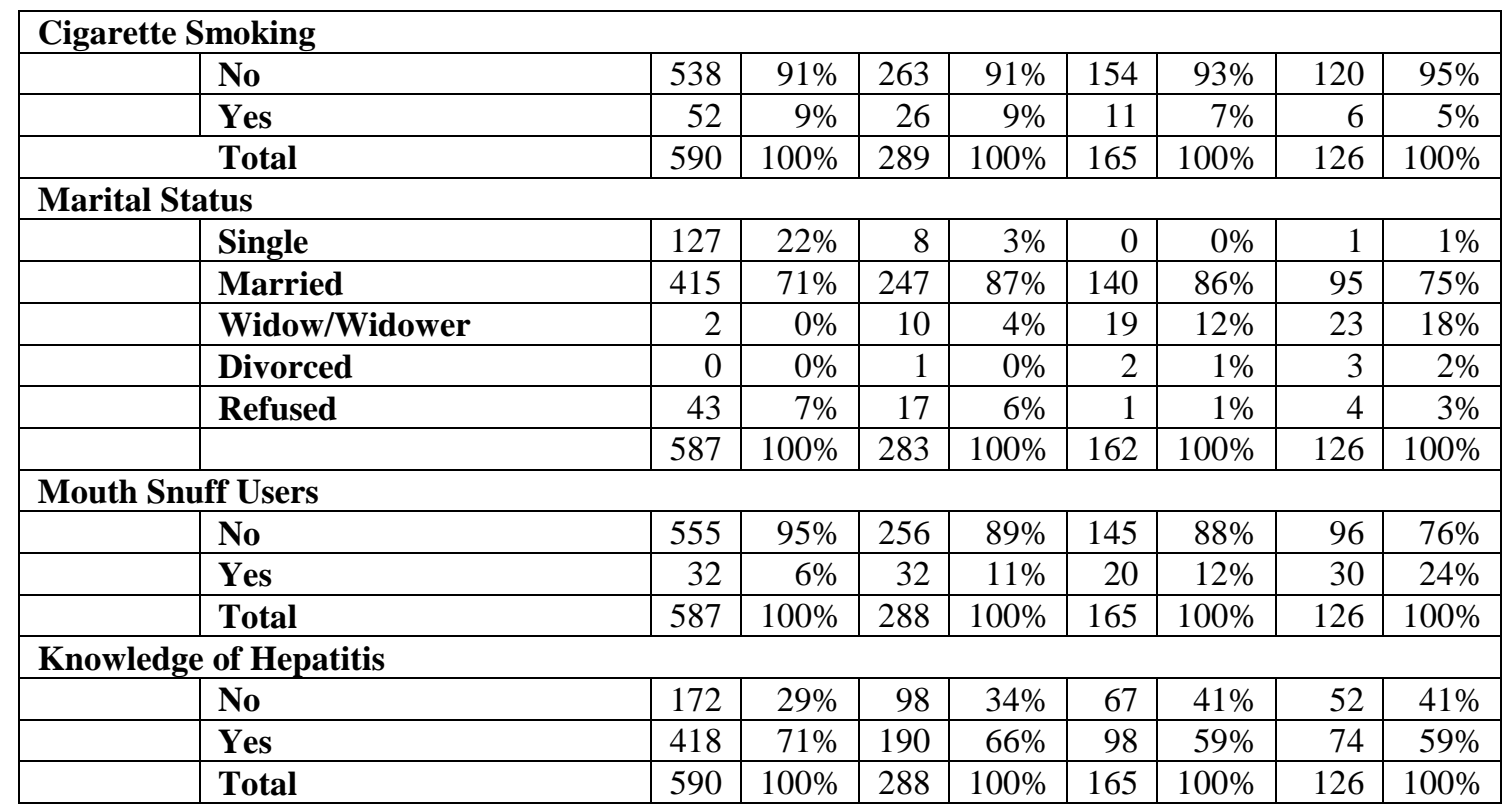

Table 2: Frequency distribution of behavioral characteristics of study participants in Kabul city by age groups

\begin{tabular}{|c|c|c|c|c|c|c|c|c|c|}
\hline \multirow[b]{2}{*}{ Variables } & \multirow{2}{*}{$\begin{array}{c}\text { Categorie } \\
\mathrm{s}\end{array}$} & \multicolumn{2}{|c|}{ 25-34 years } & \multicolumn{2}{|c|}{$35-44$ years } & \multicolumn{2}{|c|}{ 45-54 years } & \multicolumn{2}{|c|}{$55+$ years } \\
\hline & & $\mathbf{N}$ & $\%$ & $\mathbf{N}$ & $\%$ & $\mathbf{N}$ & $\%$ & $\mathbf{N}$ & $\%$ \\
\hline \multicolumn{10}{|c|}{ Blood Transfusion } \\
\hline & No & 568 & $96 \%$ & 270 & $95 \%$ & 154 & $93 \%$ & 121 & $96 \%$ \\
\hline & Yes & 22 & $4 \%$ & 15 & $5 \%$ & 11 & $7 \%$ & 5 & $4 \%$ \\
\hline & Total & 590 & $100 \%$ & 285 & $\begin{array}{r}100 \\
\%\end{array}$ & 165 & $100 \%$ & 126 & $100 \%$ \\
\hline \multicolumn{10}{|c|}{ Surgery Procedure } \\
\hline & No & 584 & $99 \%$ & 279 & $97 \%$ & 160 & $97 \%$ & 119 & $94 \%$ \\
\hline & Yes & 6 & $1 \%$ & 9 & $3 \%$ & 5 & $3 \%$ & 7 & $6 \%$ \\
\hline & Total & 590 & $100 \%$ & 288 & $\begin{array}{r}100 \\
\%\end{array}$ & 165 & $100 \%$ & 126 & $100 \%$ \\
\hline \multicolumn{10}{|c|}{ Dental Procedure } \\
\hline & No & 488 & $83 \%$ & 221 & $77 \%$ & 139 & $84 \%$ & 109 & $87 \%$ \\
\hline & Yes & 102 & $17 \%$ & 67 & $23 \%$ & 26 & $16 \%$ & 17 & $14 \%$ \\
\hline & Total & 590 & $100 \%$ & 288 & $\begin{array}{r}100 \\
\%\end{array}$ & 165 & $100 \%$ & 126 & $100 \%$ \\
\hline \multicolumn{10}{|c|}{ History of Jaundice } \\
\hline & No & 575 & $98 \%$ & 280 & $97 \%$ & 160 & $97 \%$ & 122 & $97 \%$ \\
\hline & Yes & 13 & $2 \%$ & 8 & $3 \%$ & 5 & $3 \%$ & 4 & $3 \%$ \\
\hline & Total & 588 & $100 \%$ & 288 & $\begin{array}{r}100 \\
\% \\
\end{array}$ & 165 & $100 \%$ & 126 & $100 \%$ \\
\hline \multicolumn{10}{|l|}{ Needle Injection } \\
\hline & No & 412 & $70 \%$ & 183 & $64 \%$ & 102 & $62 \%$ & 73 & $58 \%$ \\
\hline & Yes & 178 & $30 \%$ & 105 & $37 \%$ & 63 & $38 \%$ & 53 & $42 \%$ \\
\hline & Total & 590 & $100 \%$ & 288 & $\begin{array}{r}100 \\
\% \\
\end{array}$ & 165 & $100 \%$ & 126 & $100 \%$ \\
\hline \multicolumn{10}{|l|}{ Piercing } \\
\hline & No & 400 & $68 \%$ & 188 & $66 \%$ & 110 & $67 \%$ & 94 & $75 \%$ \\
\hline & Yes & 189 & $32 \%$ & 98 & $34 \%$ & 54 & $33 \%$ & 31 & $25 \%$ \\
\hline & Total & 589 & $100 \%$ & 286 & $\begin{array}{r}100 \\
\%\end{array}$ & 164 & $100 \%$ & 125 & $100 \%$ \\
\hline \multicolumn{10}{|l|}{ Tattooing } \\
\hline & No & 574 & $98 \%$ & 282 & $98 \%$ & 163 & $99 \%$ & 125 & $100 \%$ \\
\hline & Yes & 14 & $2 \%$ & 6 & $2 \%$ & 2 & $1 \%$ & 0 & $0 \%$ \\
\hline
\end{tabular}


Descriptive Study of Hepatitis B, C and HIV Infections and Associated Factors among Adult Population in

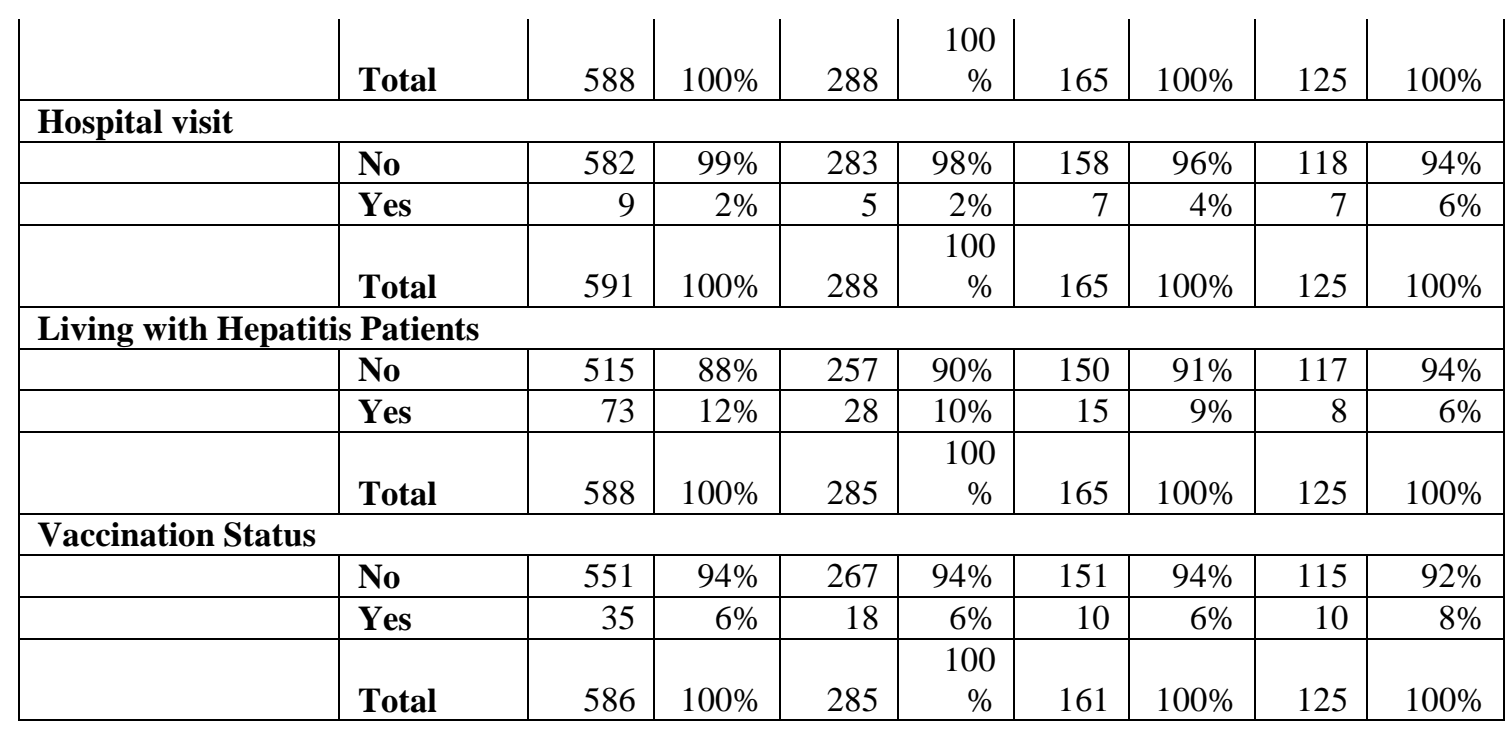

Table 3: Hepatitis B virus infection status by socieodemographic factors in study participants in Kabul city

\begin{tabular}{|c|c|c|c|c|c|c|c|c|c|}
\hline \multirow[b]{2}{*}{ Variables } & \multirow[b]{2}{*}{ Groups } & \multicolumn{2}{|c|}{ HBV Negative } & \multicolumn{2}{|c|}{ HBV Positive } & \multicolumn{2}{|c|}{ HCV Negative } & \multicolumn{2}{|c|}{ HCV positive } \\
\hline & & $\mathbf{N}$ & $\%$ & $\mathbf{N}$ & $\%$ & $\mathbf{N}$ & $\%$ & $\mathbf{N}$ & $\%$ \\
\hline \multicolumn{10}{|l|}{ Age in years } \\
\hline & $25-34$ & 578 & $51 \%$ & 15 & $43 \%$ & 590 & $51 \%$ & 3 & $23 \%$ \\
\hline & $35-44$ & 280 & $25 \%$ & 9 & $26 \%$ & 285 & $25 \%$ & 4 & $31 \%$ \\
\hline & $45-54$ & 159 & $14 \%$ & 6 & $17 \%$ & 163 & $14 \%$ & 2 & $15 \%$ \\
\hline & 54 and over & 122 & $11 \%$ & 5 & $14 \%$ & 123 & $11 \%$ & 4 & $31 \%$ \\
\hline \multicolumn{10}{|l|}{ Sex } \\
\hline & Female & 587 & $52 \%$ & 12 & $34 \%$ & 595 & $51 \%$ & 4 & $31 \%$ \\
\hline & Male & 552 & $49 \%$ & 23 & $66 \%$ & 566 & $49 \%$ & 9 & $69 \%$ \\
\hline \multicolumn{10}{|c|}{ Level of education } \\
\hline & Illiterate & 558 & $51 \%$ & 17 & $53 \%$ & 567 & $51 \%$ & 8 & $62 \%$ \\
\hline & Literate & 531 & $49 \%$ & 15 & $47 \%$ & 541 & $49 \%$ & 5 & $39 \%$ \\
\hline \multicolumn{10}{|c|}{ Knowledge of Hepatitis } \\
\hline & No & 377 & $33 \%$ & 12 & $36 \%$ & 384 & $33 \%$ & 5 & $39 \%$ \\
\hline & Yes & 759 & $67 \%$ & 21 & $64 \%$ & 772 & $67 \%$ & 8 & $62 \%$ \\
\hline \multicolumn{10}{|c|}{ Blood Transfusion } \\
\hline & No & 1082 & $96 \%$ & 31 & $94 \%$ & 1100 & $95 \%$ & 13 & $100 \%$ \\
\hline & Yes & 51 & $5 \%$ & 2 & $6 \%$ & 53 & $5 \%$ & 0 & $0 \%$ \\
\hline \multicolumn{10}{|c|}{ Surgery Procedure } \\
\hline & No & 1110 & $98 \%$ & 32 & $97 \%$ & 1129 & $98 \%$ & 13 & $100 \%$ \\
\hline & Yes & 26 & $2 \%$ & 1 & $3 \%$ & 27 & $2 \%$ & 0 & $0 \%$ \\
\hline \multicolumn{10}{|c|}{ Dental Procedure } \\
\hline & No & 932 & $82 \%$ & 25 & $76 \%$ & 947 & $82 \%$ & 10 & $77 \%$ \\
\hline & Yes & 204 & $18 \%$ & 8 & $24 \%$ & 209 & $18 \%$ & 3 & $23 \%$ \\
\hline \multicolumn{10}{|c|}{ History of Jaundice } \\
\hline & No & 1110 & $98 \%$ & 27 & $82 \%$ & 1124 & $97 \%$ & 13 & $100 \%$ \\
\hline & Yes & 24 & $2 \%$ & 6 & $18 \%$ & 30 & $3 \%$ & 0 & $0 \%$ \\
\hline \multicolumn{10}{|l|}{ Needle Injection } \\
\hline & No & 745 & $66 \%$ & 25 & $76 \%$ & 759 & $66 \%$ & 11 & $85 \%$ \\
\hline & Yes & 391 & $34 \%$ & 8 & $24 \%$ & 397 & $34 \%$ & 2 & $15 \%$ \\
\hline \multicolumn{10}{|l|}{ Piercing } \\
\hline & No & 764 & $67 \%$ & 28 & $90 \%$ & 780 & $68 \%$ & 12 & $92 \%$ \\
\hline & Yes & 369 & $33 \%$ & 3 & $10 \%$ & 371 & $32 \%$ & 1 & $8 \%$ \\
\hline \multicolumn{10}{|l|}{ Tattooing } \\
\hline & No & 1112 & $98 \%$ & 32 & $97 \%$ & 1132 & $98 \%$ & 12 & $92 \%$ \\
\hline
\end{tabular}


Descriptive Study of Hepatitis B, C and HIV Infections and Associated Factors among Adult Population in

\begin{tabular}{|l|l|r|r|r|r|r|r|r|r|} 
& Yes & 21 & $2 \%$ & 1 & $3 \%$ & 21 & $2 \%$ & 1 & $8 \%$ \\
\hline Hospitalization & No & 1111 & $98 \%$ & 30 & $91 \%$ & 1128 & $98 \%$ & 13 & $100 \%$ \\
\hline & Yes & 25 & $2 \%$ & 3 & $9 \%$ & 28 & $2 \%$ & 0 & $0 \%$ \\
\hline \multicolumn{7}{|l|}{} \\
\hline \multicolumn{2}{|l|}{ Living with Hepatitis Patients } & 1013 & $90 \%$ & 26 & $79 \%$ & 1026 & $89 \%$ & 13 & $100 \%$ \\
\hline & No & 117 & $10 \%$ & 7 & $21 \%$ & 124 & $11 \%$ & 0 & $0 \%$ \\
\hline
\end{tabular}

